\title{
Comprehensive Evaluation of PAXgene Fixation on Oral Cancer Tissues Using Routine Histology, Immunohistochemistry, and FTIR Microspectroscopy
}

\author{
Pooja Lahiri ${ }^{1, *}{ }^{\oplus}$, Suranjana Mukherjee ${ }^{1} \oplus$, Biswajoy Ghosh ${ }^{1} \oplus$, Debnath Das ${ }^{1}$, Basudev Lahiri ${ }^{2}{ }^{\oplus}$, \\ Shailendra Kumar Varshney ${ }^{2}$, Mousumi Pal ${ }^{3}$, Ranjan Rashmi Paul ${ }^{4}$ and Jyotirmoy Chatterjee ${ }^{1}$ \\ 1 School of Medical Science and Technology, Indian Institute of Technology Kharagpur, \\ Kharagpur 721302, India; suranjana.m@gmail.com (S.M.); biswajoy101@gmail.com (B.G.); \\ debnath1985@gmail.com (D.D.); jchatterjee@smst.iitkgp.ac.in (J.C.) \\ 2 Department of Electronics and Electrical Communication Engineering, Indian Institute of Technology \\ Kharagpur, Kharagpur 721302, India; blahiri@ece.iitkgp.ac.in (B.L.); skvarshney@ece.iitkgp.ac.in (S.K.V.) \\ 3 Guru Nanak Institute of Dental Sciences and Research (GNIDSR), Kolkata 700114, India; \\ drmpal62@gmail.com \\ 4 Department of Oral \& Dental Sciences, JIS University, Kolkata 700109, India; dr_rsspaul@yahoo.co.in \\ * Correspondence: poojalahiri87@gmail.com
}

check for updates

Citation: Lahiri, P.; Mukherjee, S.; Ghosh, B.; Das, D.; Lahiri, B.; Varshney, S.K.; Pal, M.; Paul, R.R.; Chatterjee, J. Comprehensive Evaluation of PAXgene Fixation on Oral Cancer Tissues Using Routine Histology, Immunohistochemistry, and FTIR Microspectroscopy. Biomolecules 2021, 11, 889. https:// doi.org/10.3390/biom11060889

Academic Editors: Agostino Guida, Giuseppe Pannone and

Marco Annunziata

Received: 19 May 2021

Accepted: 10 June 2021

Published: 15 June 2021

Publisher's Note: MDPI stays neutral with regard to jurisdictional claims in published maps and institutional affiliations.

Copyright: (c) 2021 by the authors. Licensee MDPI, Basel, Switzerland. This article is an open access article distributed under the terms and conditions of the Creative Commons Attribution (CC BY) license (https:// creativecommons.org/licenses/by/ $4.0 /)$.

\begin{abstract}
The choice of tissue fixation is critical for preserving the morphology and biochemical information of tissues. Fragile oral tissues with lower tensile strength are challenging to process for histological applications as they are prone to processing damage, such as tissue tear, wrinkling, and tissue fall-off from slides. This leads to loss of morphological information and unnecessary delay in experimentation. In this study, we have characterized the new PAXgene tissue fixation system on oral buccal mucosal tissue of cancerous and normal pathology for routine histological and immunohistochemical applications. We aimed to minimize the processing damage of tissues and improve the quality of histological experiments. We also examined the preservation of biomolecules by PAXgene fixation using FTIR microspectroscopy. Our results demonstrate that the PAXgene-fixed tissues showed significantly less tissue fall-off from slides. Hematoxylin and Eosin staining showed comparable morphology between formalin-fixed and PAXgene-fixed tissues. Good quality and slightly superior immunostaining for cancer-associated proteins p53 and CK5/6 were observed in PAXgene-fixed tissues without antigen retrieval than formalin-fixed tissues. Further, FTIR measurements revealed superior preservation of glycogen, fatty acids, and amide III protein secondary structures in PAXgene-fixed tissues. Overall, we present the first comprehensive evaluation of the PAXgene tissue fixation system in oral tissues. This study concludes that the PAXgene tissue fixation system can be applied to oral tissues to perform diagnostic molecular pathology experiments without compromising the quality of the morphology or biochemistry of biomolecules.
\end{abstract}

Keywords: PAXgene tissue fixation; formalin fixation; oral epithelial dysplasia; oral squamous cell carcinoma; immunohistochemistry; spectral histology; FTIR

\section{Introduction}

Pre-analytical handling of surgical, biopsy, or post-mortem tissue is a critical step that influences the quality of the collected biospecimen and determines the outcome of the diagnostic methods applied [1]. Ten percent neutral buffered formalin (NBF) is the fixative reagent of choice for biological tissues in the medical community for almost a century because of its excellent preservation capability [2]. The processing of tissues with NBF is relatively cheap and hassle-free and can be applied to any type of biological tissue across species. The NBF-fixed paraffin-embedded (FFPE) tissue blocks can be stored for an extended period of time, allowing the creation of disease-specific archives (tissue-biobanks) 
of diagnostically relevant tissues [1,2]. These tissue biobanks are often used in medical research to investigate and teach the pathogenesis of a variety of diseases [3,4].

In recent years, molecular diagnostic pathology has widened its approaches to assess disease progression. Histo-morphological assessment with alterations in genetic material and functional biochemistry of disease-associated biomolecules is fast becoming the norm for a comprehensive diagnosis $[1,2,4,5]$. Therefore, enormous efforts are being made by the scientific and clinical community to isolate and preserve a good quality of nucleic acids and proteins from FFPE tissue blocks for molecular diagnostic assays. However, the success rates of these efforts are marginalized by the harsher treatments required to break the nucleic acid and protein crosslinks formed by NBF fixation, rendering the isolated samples not suitable for molecular analysis [6,7]. Currently, snap freezing of tissues and storage at low temperatures in liquid nitrogen is considered appropriate for molecular analysis $[3,8]$. Nevertheless, liquid nitrogen preservation comes with the possibility of intracellular ice build-up, leading to defects in the morphology of tissue [9]. Hence, the choice of tissue fixative should be made carefully when new biomarker studies on disease progression are initiated to ensure that the antigenicity of the epitopes is not compromised, and the chemistry of crucial biomolecules is preserved. Newer methods of fixation and preservation of tissues are always wanted in clinical diagnostics.

In this study, we have characterized the new PAXgene tissue fixation and stabilization reagent on oral buccal mucosal biopsied tissues for routine histological and immunohistochemical applications [8]. Oral buccal mucosal tissue has the lowest tensile strength among other intraoral sites, such as the gingiva and hard palate [10]. Hence, it is not surprising that oral buccal mucosal tissue suffers from histological processing errors, such as tissue fall-off from the slides and wrinkling. We observed continuing difficulty in handling FFPE oral buccal mucosal tissues for immunohistochemical studies and routine histological staining, leading to delays in experimental results, non-reproducibility of data, and loss of useful molecular information. Therefore, we aimed to optimize the oral tissue fixation and histological staining procedures with PAXgene tissue fixation reagents. According to the manufacturer (QIAGEN), the PAXgene tissue fixation system is a non-toxic method of tissue fixation consisting of mixtures of alcohols, acetic acid, and soluble organic compounds [8]. It is claimed that the PAXgene fixation reagent rapidly preserves the morphology of the biomolecules [11]. The fixation is followed by adding a stabilization reagent consisting of a mixture of alcohol that enhances the stability of the bio-specimens for the transport of samples and long-term preservation. We have further investigated the preservation of biomolecules by PAXgene fixation by FTIR microspectroscopy. The FTIR spectrum provides information on the overall biochemical status of major biomolecules, i.e., nucleic acids, lipids, and proteins in tissue. The variations in biomolecule chemistry in response to external factors (in this study - tissue fixation methods) can be calculated by assessing the changes in infrared spectra [12]. In this study, we thoroughly evaluated the PAXgene fixation with conventional formalin fixation with an aim to minimize the processing damage of tissues and improve the quality of the histopathological diagnosis.

\section{Materials and Methods}

\subsection{Collection of Tissue and Fixation}

Patients showing clinical symptoms of oral pre-cancers and oral squamous cell carcinoma (OSCC) were chosen for the biopsy procedure. All biopsies were performed at Guru Nanak Institute of Dental Sciences and Research (GNIDSR). A wedge biopsy was performed to collect representative tissues from pre-cancerous or cancerous areas in the buccal mucosa of selected patients. Another tissue biopsy was performed on the adjacent buccal mucosa to the pre-cancerous or cancerous site, clinically representing a normal architecture or normal oral mucosa (NOM). Further, all types of collected biopsied tissues were divided into two equal parts. One part of the tissue was added to freshly prepared $10 \%$ NBF (tissue_F) and the other part of the tissue was added into PAXgene tissue fix (QIAGEN) reagent (tissue_P). After $48 \mathrm{~h}$ of fixation, fresh $10 \%$ NBF formalin was added to the 
tissue_F, and the PAXgene tissue stabilizer reagent was added to the tissue_P followed by gentle agitation (250 rpm) for $72 \mathrm{~h}$. Post stabilization of tissue_P, both tissue_F and tissue_P were processed for paraffin embedding according to the established protocol reported elsewhere $[3,8,13]$. In this article, formalin-fixed paraffin-embedded tissues and PAXgene-fixed paraffin-embedded tissues will be referred to as FFPE and PFPE, respectively. The sample size for the different experimental set-ups is mentioned whenever required. This study was performed with the informed consent of all individuals and approved by the institutional ethics committee (GNIDSR/IEC/07/16).

\subsection{Hematoxylin and Eosin Staining}

Histological assessment of FFPE and PFPE tissues in terms of preservation of morphology (overall morphology and nuclear, cytoplasmic, and membrane details) was performed on $4 \mu \mathrm{m}$ tissue sections using hematoxylin and eosin (H\&E) staining and verified by at least three certified oral pathologists from GNIDSR, Kolkata. The tissue sections were mounted on AUTOFROST charged adhesion microscopic slides (\#20190710; Cancer Diagnostics Inc., , Durham, NC, USA.

For H\&E staining, FFPE and PFPE tissue sections were deparaffinized at $65^{\circ} \mathrm{C}$ for $30 \mathrm{~min}$, followed by xylene treatment for $20 \mathrm{~min}$. The rehydration of the tissue sections was performed with decreasing gradients of ethanol (100\%, 90\%,70\%,50\%, and MilliQ water). Tissue slides were stained by immersing in Mayer's Hematoxylin solution (\#51275, Sigma Aldrich, Bangalore, India) for $1 \mathrm{~min}$, followed by a tap water wash for $5 \mathrm{~min}$. Counterstaining with Eosin Y stain (\#E4009, Sigma Aldrich) was performed for 20 s. Dehydration with an increasing gradient of ethanol was immediately done after counterstaining. The slides were cleared with xylene for 5 min and mounted with DPX. The integrated density value of the hematoxylin and eosin stain for PFPE-fixed and FFPE-fixed NOM, dysplasia, and OSCC tissues were calculated using the ImageJ (NIH, Bethesda, MD, USA) color deconvolution tool (HE filter,). Statistical analysis was performed using GraphPad Prism software (GraphPad, San Diego, CA, USA).

\subsection{Immunohistochemistry}

Immunohistochemical staining for epithelial cytokeratin CK5/6 (\#ab5312 and \# ab18586, Abcam, Cambridge, UK) and tumor suppressor protein p53 (\#ab131442, Abcam, Cambridge, UK) was performed on $4 \mu \mathrm{m}$ tissue sections prepared from FFPE and PFPE blocks according to manufacturer's instructions (\#K8023, DAKO, Santa Clara, CA, USA), with modifications in the antigen retrieval methodology (Table S2). Both FFPE and PFPE tissue slides were deparaffinized at $65^{\circ} \mathrm{C}$ for $30 \mathrm{~min}$, followed by xylene treatment for $30 \mathrm{~min}$. The tissue sections were re-dehydrated by immersing the slides consecutively in $100 \%$ ethanol, $90 \%$ ethanol, 70\% ethanol, and 50\% ethanol for 2 min each. All the tissue slides were given a brief MilliQ water wash prior to antigen retrieval. As oral biopsied tissues are sensitive to tissue fall-off during microwave/pressure cooker procedures, antigen retrieval for FFPE tissue was performed by immersing the slides with tissue sections in TRIS EDTA $\mathrm{pH} 9$ buffers at $65^{\circ} \mathrm{C}$ for $30 \mathrm{~min}$ to minimize tissue disruption (Table S2). Identical antigen retrieval conditions were maintained for PFPE tissue. In addition, PFPE tissue sections were also processed without heat-induced antigen retrieval. After antigen retrieval (if performed), tissue slides were brought back to room temperature prior to the antibody steps. Primary antibody dilution was prepared according to the manufacturer's instruction (p53:1:500; CK5/6, 1:500) in 1\% BSA + TBS. The tissue slides were incubated with primary antibody overnight. The next day, ready to use secondary antibody (EnVision ${ }^{\mathrm{TM}}$ FLEX/HRP; DAKO) was added to the TBS-washed tissue sections and incubated for $1 \mathrm{~h}$. Following secondary antibody application, sections were properly washed in TBS, and $\mathrm{DAB}$ chromogen was added for the color reaction. The appropriate time was noted for the color development (p53; $2.5 \mathrm{~min}$ and CK5/6; $1 \mathrm{~min}$ ) and was maintained for all the experiments performed. All the tissue slides were counterstained with Mayer's Hematoxylin, dehydrated using ethanol, and mounted using DPX (\#06522, Merck, Bangalore, 
India) (Method S1). The integrated density value of each immuno-stain (p53 and CK5/6) for PFPE-fixed and FFPE-fixed NOM, dysplasia, and OSCC tissues were calculated using the ImageJ (NIH, Bethesda, MD., USA) color deconvolution tool (H DAB filter). Statistical analysis was performed using GraphPad Prism software (GraphPad Prism, San Diego, CA, USA).

\subsection{Microscopy}

H\&E and immunohistochemistry images were captured using a brightfield microscope (Leica Microsystems, Wetzlar, Germany) at different magnifications $(10 \times, 20 \times$, and $40 \times$ ). Scale bars were added using Image J. All the H\&E images and IHC images were assembled as figures using ImageJ, Adobe Illustrator CC (Adobe, San Jose, CA, USA), or MS PowerPoint software.

\subsection{FTIR Microspectroscopy}

Tissue sections of $4 \mu \mathrm{m}$ in thickness were prepared from both FFPE and PFPE blocks for FTIR microspectroscopy. Of note, $4 \mu \mathrm{m}$ sections for H\&E staining and immunohistochemistry were prepared simultaneously and are considered parallel sections for selected experiments. The $4 \mu \mathrm{m}$ tissue sections on AUTOFROST slides were baked at $60{ }^{\circ} \mathrm{C}$ for $30 \mathrm{~min}$, followed by two changes of xylene for deparaffinization. Immediately, the tissue sections were dehydrated by immersing the slides in 100\% ethanol for $10 \mathrm{~min}$. The tissue sections were then allowed to air dry for $30 \mathrm{~min}$ at room temperature. The tissue sections were analyzed under a LUMOS-II FTIR microspectroscope (Bruker, Billerica, MA, USA) with a liquid nitrogen-cooled mercury-cadmium-telluride $64 \times 64$-pixel focal plane array (FPA) detector within the same day post dehydration. Histologically diagnosed FFPE-NOM, PFPE-NOM, and FFPE-OSCC, PFPE OSCC were used for measurement of the spectra. Spectroscopic imaging data were acquired in reflection mode. Background spectra were collected from a region free of tissue of the FTIR-reflective slide. Spectral data were recorded using a mirror speed of $1 \mathrm{~cm}^{-1}$, a spectral resolution of $4 \mathrm{~cm}^{-1}$, and using an acquisition time of $6 \mathrm{~s}$ (64 scans) per measurement. Twenty tissues from each group were used for spectral data acquisition. In total, 200 spectral measurements were recorded for FFPE-NOM $\left(\mathrm{N}^{\text {spectra }}=100\right)$ and PFPE-NOM $\left(\mathrm{N}^{\text {spectra }}=100\right)$, and 300 spectral measurements were recorded for FFPE-OSCC $\left(\mathrm{N}^{\text {spectra }}=150\right)$ and PFPE-OSCC tissue $\left(\mathrm{N}^{\text {spectra }}=150\right)$. Pathologically similar regions of interest exhibiting a normal oral morphology of the epithelium were chosen for spectral measurements from the NOM group of tissues. Moreover, epithelial islands from well-differentiated squamous cell carcinoma tissues were chosen for spectral measurements from the OSCC group of tissues. Average spectra were calculated and smoothened for 25 smoothening points (Savitzky Golay algorithm) for each tissue group only after ascertaining no significant variation between the average spectra and individual spectra taken from each region of interest. No other post-processing of spectra was performed. The band position for each bio-component was calculated using the peak analyzer algorithm of Origin Pro software (Northampton, MA, USA).

Sample collection and the experimental set-ups are depicted in Figure 1. 


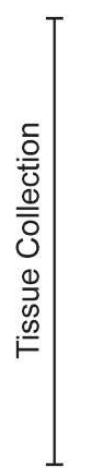

Fresh NBF

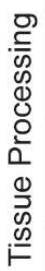

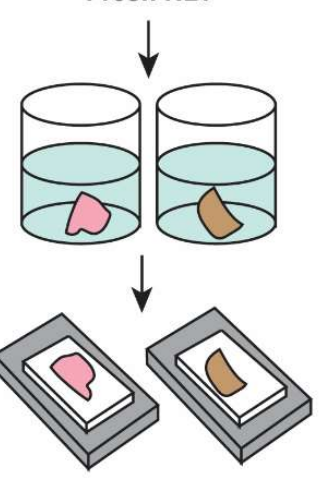

FFPE-NOM FFPE-OSCC

Tissue Block Tissue Block
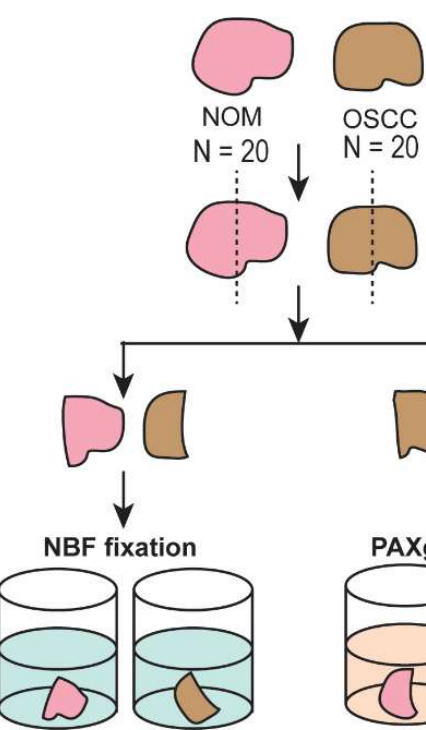

OSCC

$N=20$

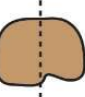

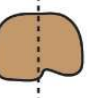
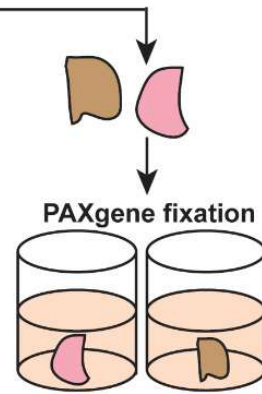

PAXgene Stabilization

Pax

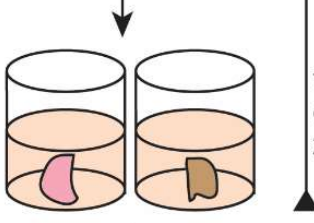

Gentle Agitation

250rpm

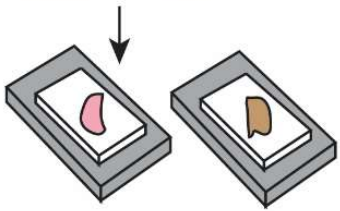

PFPE-NOM PFPE-OSCC

Tissue Block Tissue Block

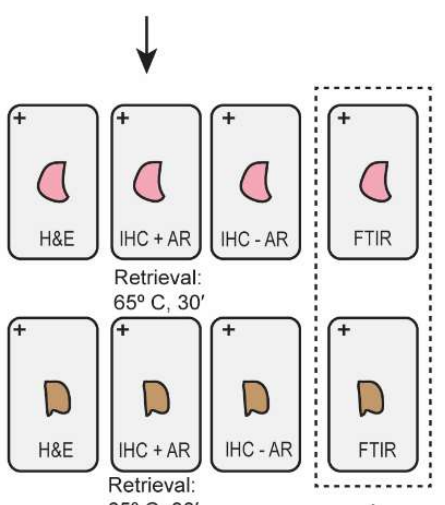

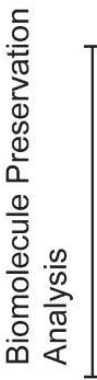

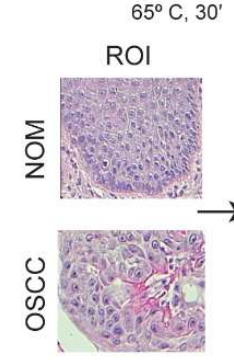

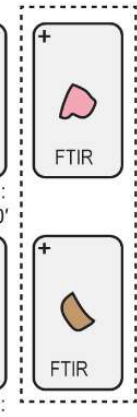

$\downarrow$

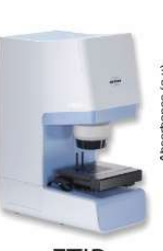

FTIR
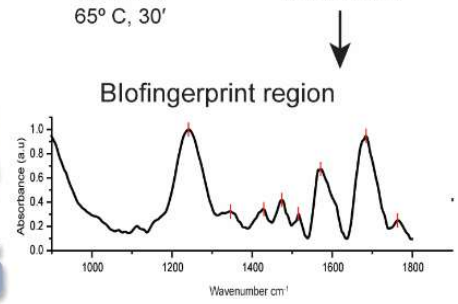

$\mathrm{N}$ spectra NOM $=100$

$\mathrm{N}$ spectra OSCC $=150$
1. Selection of Tissues by Oral-Oncopathologists

- Biopsied oral squamous cell carcinoma tissue (OSCC) tissue

- Biopsied tissue adjacent to OSCC area showing

normal architecture (NOM)

2. Dividing the tissue into two section for fixation using $10 \%$ Neutral Buffered Formalin or PAXgene

3. Fixation of NOM or OSCC tissue using $10 \%$ NBF or PAXgene tissue fix solution

4. Paraffin embedding of NOM and OSCC samples and preparation of FFPE and PFPE tissue blocks

5. Tissue sectioning $(4 \mu \mathrm{m})$ from FFPE and PFPE tissue blocks for $\mathrm{HE}$ and IHC experiments using microtome

- Documentation of number of cases of tissue fall-off after - Deparaffinization or rehydration

- Heat induced antigen retrieval

- Percentage of tissue area loss noted in H\&E stained tissue section for each sample

6. FTIR measurements taken from pathologically similar region of interest for grouped tissues of NBF and PAXgene fixation

Figure 1. Sample collection and experimental setup of the study. Abbreviations: H\&E, hematoxylin and eosin; IHC, immunohistochemistry; R, retrieval; FTIR, Fourier-transform infrared; AR, antigen retrieval. 


\section{Results}

\subsection{Histological Comparison of FFPE and PFPE Tissues Using HEE Staining}

FFPE oral buccal mucosal tissues with a normal architecture (NOM) are challenging to process for histological staining. We frequently experienced tissue tear, wrinkling, and fall-off of the tissue-section from slides, either after deparaffinization at $65{ }^{\circ} \mathrm{C}$ or after rehydration with a decreasing gradient of alcohol. We maintained a log of all the FFPE samples received between 2019 and 2020 from the GNIDSR tissue bank and documented the cases of tissue fall-off from slides. Around $28.6 \%$ of the FFPE-NOM cases could not be processed further for histological staining after the rehydration step due to the fall-off of tissue sections from the slides (Table 1). However, only 5.5\% of FFPE-OSCC cases suffered tissue section fall-off from slides (Table 1).

Table 1. Documentation of cases of tissue section fall-off from slides during sample processing steps for histochemical staining experiments for a period of 1 year (2019-2020) for FFPE tissues from the tissue bank of GNIDSR.

\begin{tabular}{lccc}
\hline & $\begin{array}{c}\text { Total Number of } \\
\text { FFPE Tissue }^{\text {a }}\end{array}$ & $\begin{array}{c}\text { Cases of Tissue } \\
\text { Fall-Off }\end{array}$ & Percentage \\
\hline Number of NOM samples & 35 & 10 & 28.57 \\
Number of OSCC samples & 73 & 8 & 5.48 \\
\hline
\end{tabular}

a Number of tissue samples (FFPE) received during 2019-2020 from GNIDSR, Kolkata. ${ }^{*}$ Number of cases of tissue fall-off from slides after either deparaffinization or rehydration of the tissue section with a decreasing gradient of alcohol. Abbreviations: NOM, normal oral mucosa; OSCC, oral squamous cell-carcinoma; FFPE, formalin-fixed paraffin embedded; PFPE, PAXgene-fixed paraffin embedded.

To minimize the delay in experimentation due to the loss of tissue sections during the processing of FFPE samples, we used PAXgene as an alternative tissue fixation method for oral buccal mucosal tissue. We investigated whether the change in fixation method of oral tissues reduces the problem of tissue section fall-off, tissue tear, or wrinkling. For this purpose, we selected a total of 40 fresh biopsied tissues (NOM: $n=20$; OSCC: $n=20$ ), divided them into two parts, and fixed them in freshly prepared $10 \%$ NBF or PAXgene tissue fixative solution (Figure 1). Tissue sections of $4 \mu \mathrm{m}$ in thickness were prepared from FFPE and PFPE tissue blocks and processed for H\&E staining. We noted seven cases of tissue section fall-off for the FFPE-NOM $(n=20)$ tissue sample compared to three cases for the PFPE-NOM tissue samples $(n=20)$ (Table 2). Further analysis on H\&E-stained sections showed the percentage of loss of epithelial and sub-epithelial tissue area due to tissue tear or wrinkling, which was more prominent in FFPE-NOM samples than PFPE-NOM samples (Table S1). Moreover, no cases of tissue section fall-off were noted for the PFPE-OSCC tissue samples $(n=20)$, and only one case was noted for the FFPE-OSCC tissue samples (Table 2).

Table 2. Documentation of cases of tissue section fall-off from slides during the sample processing steps for histochemical staining experiments for matched FFPE and PFPE tissue biopsies.

\begin{tabular}{|c|c|c|c|c|c|c|}
\hline & $\begin{array}{l}\text { Total Number of } \\
\text { FFPE Tissues }\end{array}$ & $\begin{array}{c}\text { Cases of Tissue } \\
\text { Fall-Off * }\end{array}$ & Percentage & $\begin{array}{l}\text { Total Number of } \\
\text { PFPE Tissues a }\end{array}$ & $\begin{array}{l}\text { Cases of Tissue } \\
\text { Fall-Off * }\end{array}$ & Percentage \\
\hline $\begin{array}{c}\text { Number of } \\
\text { NOM samples }\end{array}$ & 20 & 7 & 35.00 & 20 & 3 & 15.00 \\
\hline $\begin{array}{l}\text { Number of } \\
\text { OSCC samples }\end{array}$ & 20 & 1 & 5.00 & 20 & 0 & 0.00 \\
\hline
\end{tabular}

a Number of tissue samples (FFPE or PFPE) received from GNIDSR, Kolkata, for the comparative study. * Number of cases of tissue fall-off from slides after either deparaffinization or rehydration of the tissue section with a decreasing gradient of alcohol. Abbreviations: NOM, normal oral mucosa; OSCC, oral squamous cell-carcinoma; FFPE, formalin-fixed paraffin-embedded; PFPE, PAXgene-fixed paraffinembedded. 
In terms of overall histology, the morphology of the H\&E-stained sections of FFPENOM and PFPE-NOM or FFPE-OSCC and PFPE-OSCC was similar (Figure 2). A slightly enhanced eosinophilic reaction was observed in both the epithelium and sub-epithelium regions of PFPE-NOM and PFPE-OSCC tissues (Figure 2A-F). This enhanced the cytoplasmic and nuclear details and did not hamper the histological evaluation of the disease morphology (Figure 2B,D).
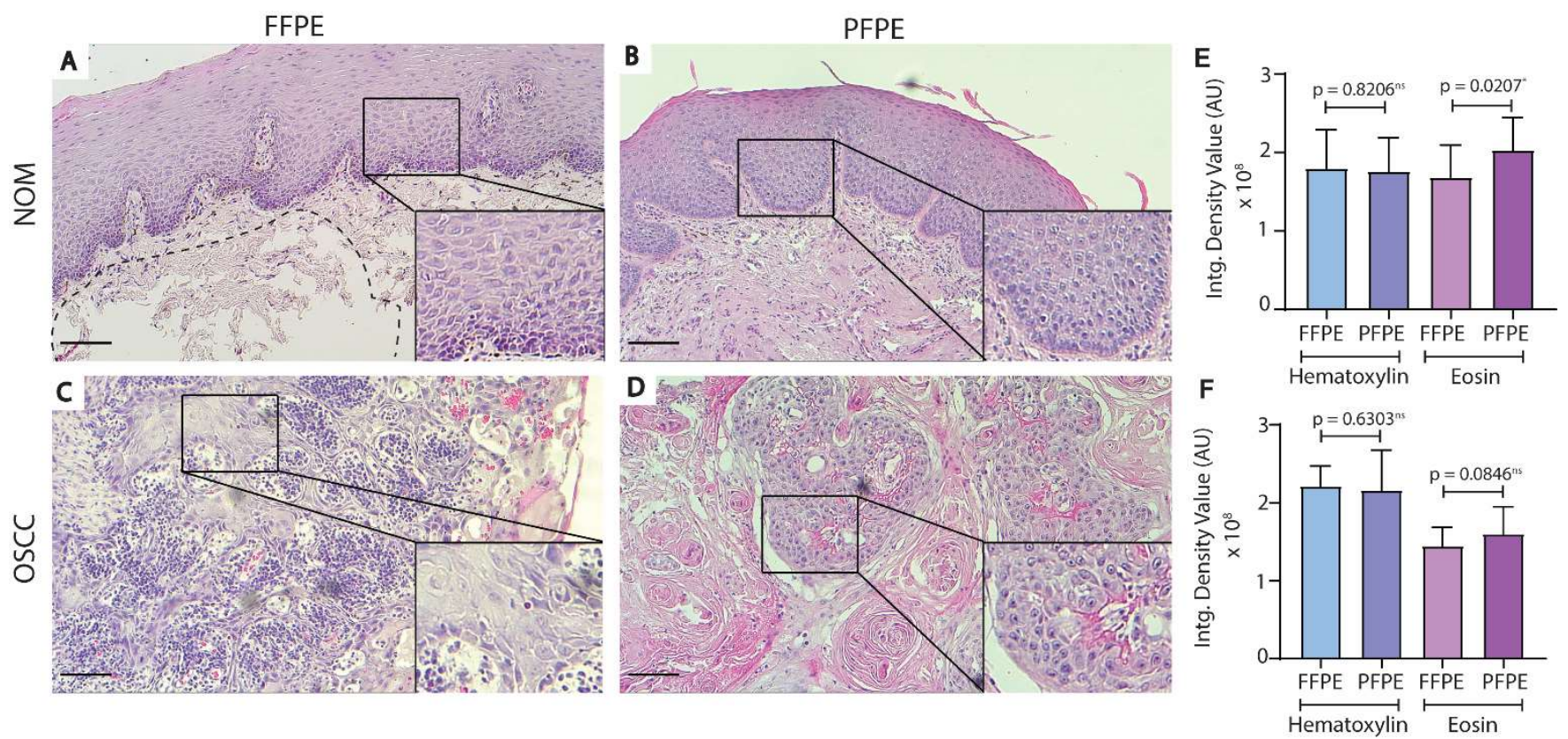

Figure 2. Morphological comparisons of PFPE and FFPE tissues. Hematoxylin and eosin staining was performed on FFPE NOM and OSCC tissues (A,C) and PFPE NOM and OSCC tissues (B,D). PFPE tissues were more eosinophilic than FFPE tissues (A,B) — corresponding integrated density value plot $(\mathbf{E})$ —and $(\mathbf{C}, \mathbf{D})$ —corresponding integrated density value plot (F). Morphology of the epithelium layers and sub-epithelium region was well-preserved in PFPE-NOM tissue (B) and was comparable to FFPE-NOM tissue (A). Squamous cell carcinoma was well-represented in both PFPE (C) and FFPE tissue (D). High magnification insets for each panel (A-D) shows the morphology of the epithelial cells in NOM (A,B) and OSCC (C,D). An example of loss of tissue area (dotted lines) due to sample processing was shown in FFPE-NOM tissue (A). Magnification $=10 \times$; Scale bar $=50 \mu \mathrm{m} . p<0.05 *$ (student's $t$-test). Abbreviations: PFPE, PAXgene-fixed paraffin embedded; FFPE, formalin-fixed paraffin embedded; NOM, normal oral mucosa; OSCC, oral squamous cell carcinoma; Intg., integrated.

\subsection{PFPE Tissues Do Not Require Heat-Induced Antigen Retrieval for Immunohistochemistry}

After we observed comparatively fewer tissue section fall-off cases for PFPE tissue samples, we tested the PFPE-NOM and PFPE-OSCC tissue samples for immunohistochemical applications. In particular, we assessed the expression of tumor suppressor protein p53 and cytoskeletal cytokeratins (CK) 5 and 6 by performing immunohistochemistry with respective antibodies on FFPE and PFPE tissue sections. Our laboratory experienced an increase in tissue fall-off cases from slides after the heat-induced antigen retrieval step for FFPE tissues (Table 3). We tried various heating and pressure conditions for optimum antigen retrieval with FFPE-NOM tissues $(n=20)$ (Table S2) and to minimize tissue fall-off and damage (Table 4). The optimum antigen-retrieval was observed after heating the samples at $65^{\circ} \mathrm{C}$ for $30 \mathrm{~min}$ with tris-citrate buffer, $\mathrm{pH}$ 6, in a water bath (Table S2). 
Table 3. Documentation of cases of tissue section fall-off from slides during sample processing steps for immunohistochemical staining experiments for a period of 1 year (2019-2020) for FFPE tissues.

\begin{tabular}{cccccc}
\hline & $\begin{array}{c}\text { Total Number of } \\
\text { FFPE Tissues * }\end{array}$ & $\begin{array}{c}\text { Cases of Tissue Fall-Off } \\
\text { after D or R Steps }\end{array}$ & $\begin{array}{c}\text { Cases of Tissue } \\
\text { Fall-Off after AR }\end{array}$ & $\begin{array}{c}\text { Total Cases of } \\
\text { Tissue Fall-Off }\end{array}$ & $\begin{array}{c}\text { Number of Cases } \\
\text { Left for IHC Expts. }\end{array}$ \\
\hline $\begin{array}{c}\text { Number of } \\
\text { NOM samples } \\
\text { Number of }\end{array}$ & 35 & 12 & 18 & 30 & 5 \\
OSCC samples & 73 & 3 & 43 & 46 & 30 \\
\hline
\end{tabular}

* Number of tissue samples (FFPE) received during 2019-2020 from GNIDSR, Kolkata. Abbreviations: D, deparaffinization; R, rehydration; NOM, normal oral mucosa; OSCC, oral squamous cell-carcinoma; FFPE, formalin-fixed paraffin embedded; AR, antigen retrieval; IHC, immunohistochemistry.

Table 4. Documentation of cases of tissue section fall-off from slides during sample processing steps for immune-histochemical staining experiments for matched PFPE and FFPE tissue biopsies.

\begin{tabular}{lcc}
\hline & $\begin{array}{c}\text { Number of NOM } \\
\text { Samples }\end{array}$ & $\begin{array}{c}\text { Number of OSCC } \\
\text { Samples }\end{array}$ \\
\hline Total number of FFPE tissues & 20 & 20 \\
Cases of tissue fall-off after D or R steps & 6 & 2 \\
Cases of tissue fall-off after AR & 12 & 9 \\
Total cases of tissue fall-off & 18 & 11 \\
Number of cases left for IHC experiments & 2 & 9 \\
Percentage of tissues left for IHC experiments & 10 & 45 \\
\hline Total number of PFPE tissues & 20 & 20 \\
Cases of tissue fall-off after D or R steps & 3 & 1 \\
Cases of tissue fall-off after AR & 5 & 3 \\
Total cases of tissue fall-off & 7 & 4 \\
Number of cases left for IHC experiments & 13 & 16 \\
Percentage of tissues left for IHC experiments & 65 & 80
\end{tabular}

Abbreviations: D, deparaffinization; R, rehydration; NOM, normal oral mucosa; OSCC, oral squamous cellcarcinoma; FFPE, formalin-fixed paraffin embedded; AR, antigen retrieval; IHC, immunohistochemistry.

Unlike formalin, the PAXgene tissue fixation solution does not form methylene crosslinks in tissues [8]. Hence, a protocol deviation was introduced for PFPE tissues where a parallel section was not subjected to antigen retrieval (Figure 3B,E). We observed cytoplasmic and nuclear expression of p53 in the basal and suprabasal layer of the epithelium and no difference in p53 immuno-expression between PFPE-NOM tissue sections with and without antigen retrieval (Figure $3 \mathrm{~A}, \mathrm{~B}, \mathrm{G}$ ). However, the intensity of the p53 immuno-expression was significantly less in the suprabasal layer, and no or noticeably light staining was observed in FFPE-NOM tissue when compared to PFPE-NOM tissues (Figure $3 \mathrm{C}$ vs. Figure $3 \mathrm{~A}, \mathrm{~B}, \mathrm{G}$ ) in replicated experiments even with an increase in the timing of DAB staining to $2.5 \mathrm{~min}$ (data not shown). We observed a homogenous cytoplasmic expression of CK5/ 6 in the epithelium of PFPE-NOM and FFPE-NOM tissue; however, similar to p53, the intensity of expression of CK5/6 was significantly less (Figure $3 \mathrm{H}$ ) in the epithelium layers of FFPE-NOM tissue (Figure 3F vs. Figure 3D,E). Furthermore, no difference in CK5 / 6 immuno-expression was observed between PFPE-NOM tissues with or without antigen retrieval (Figure 3D,E,H).

Next, we analyzed the expression profile of p53 and CK5/6 in cases of dysplasia and OSCC. A higher expression of p53 and CK5/6 was observed in dysplasia and OSCC tissues than NOM tissues (Figure 4 vs. Figure 3). No significant differences in the expression pattern of $\mathrm{p} 53$ and CK5/6 in dysplasia or OSCC were observed between PFPE tissues with antigen retrieval (Figure 4A,D,G,J); PFPE tissues without antigen retrieval (Figure $4 \mathrm{~B}, \mathrm{E}, \mathrm{H}, \mathrm{K}$ ); and FFPE tissues (Figure $4 \mathrm{C}, \mathrm{F}, \mathrm{I}, \mathrm{L}$ ). However, the density value plot for p53 and CK5 $/ 6$ showed a trend of a decrease in immuno-staining for both proteins in FFPE tissues compared to PFPE tissues (Figure 4M-P). Furthermore, p53 was observed in the cytoplasm and nucleus of the basal and suprabasal cells in dysplasia (Figure $4 \mathrm{~A}-\mathrm{C}$ ) and epithelial islands in OSCC (Figure 4D-F). Likewise, CK5/6 expression was cytoplasmic 
and spread homogeneously throughout the epithelium layers in dysplasia (Figure 4G-I). In OSCC, cytoplasmic expression of CK5/6 was homogenously expressed in the cytoplasm of epithelial islands and the keratin pearls (Figure $4 \mathrm{~J}-\mathrm{L}$ ).
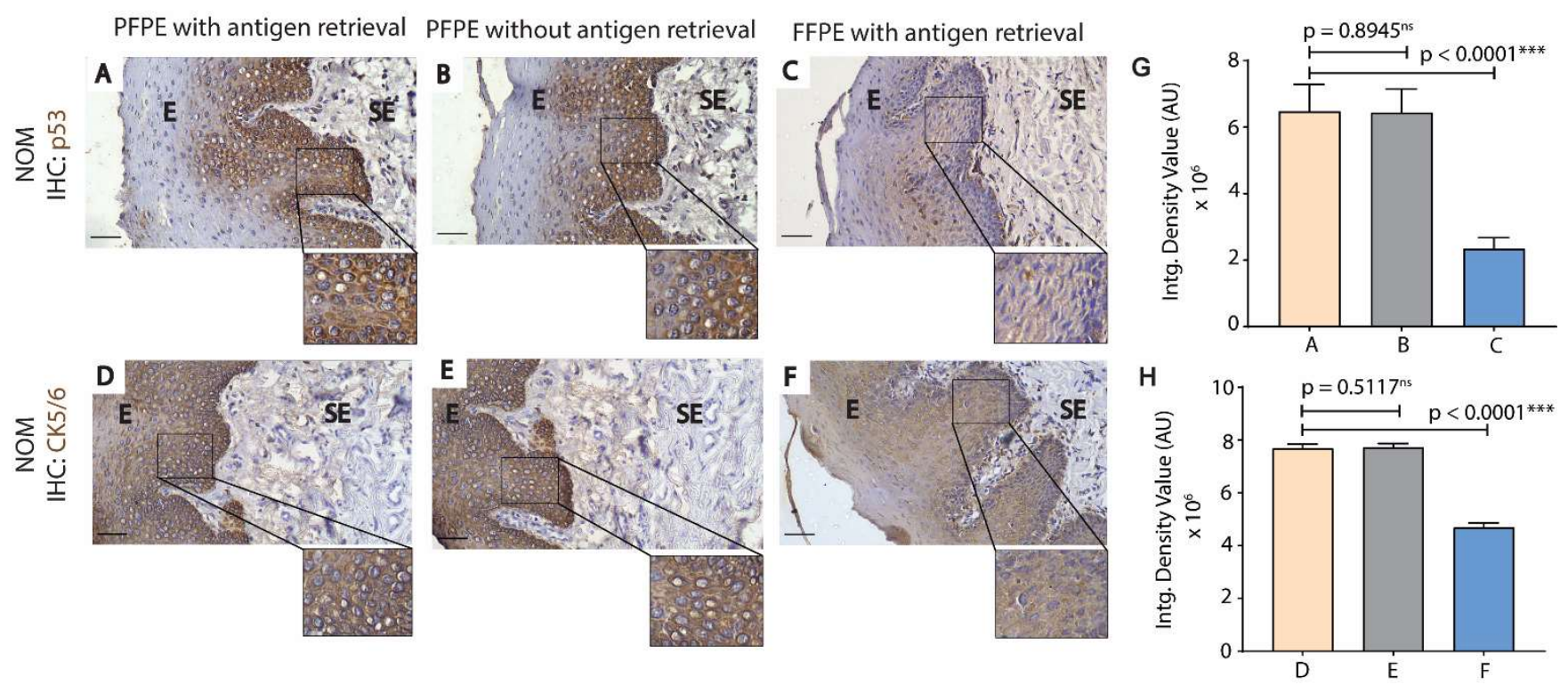

Figure 3. Heat-induced antigen retrieval is not essential for PFPE-NOM tissues. Immunohistochemistry with antibodies against p53 (A-C; upper panel) and CK5/6 (D,E; lower panel) was performed on PFPE-NOM (A,B,D,E) and FFPE-NOM (C,F) tissue sections. Parallel tissue sections of PFPE-NOM samples were subjected to primary antibody (p53 or CK5/6) incubation with a prior antigen retrieval step (A,D) and without an antigen retrieval step (B,E). Antigen retrieval was performed on tissue sections of FFPE-NOM samples (C,F) before antibody (p53 or CK5/6) incubation (C,F). p53 immunostaining was observed in basal and suprabasal layers of the epithelium in PFPE-NOM tissues with (A) or without antigen retrieval (B). However, the intensity of p53 immuno-staining was markedly less in FFPE-NOM tissues (corresponding integrated density value plot (G) for A-C) with no or noticeably light staining of p53 in basal cells. Similarly, CK5/6 immuno-staining was observed homogenously throughout the epithelium in PFPE-NOM tissues with (D) and without antigen retrieval (E). In FFPE-NOM tissue, CK5/6 immuno-staining was observed through-out the epithelium, but with markedly less intensity than PFPE-NOM tissues (corresponding integrated density value plot (H) for D-F). The incubation time for DAB chromogen was $2.5 \mathrm{~min}$ for p53 antibody and $1 \mathrm{~min}$ for CK5/6 antibody. Magnification $=20 \times$; Scale bar $=25 \mu \mathrm{m} . p<0.0001^{* * *}$ (student $t$-test). Abbreviations: E, epithelium, SE, sub-epithelium; AR, antigen retrieval; FFPE, formalin-fixed paraffin embedded; PFPE, PAXgene-fixed paraffin embedded; NOM, normal oral mucosa; CK, cytokeratin; Intg, integrated.

\footnotetext{
3.3. FTIR Microspectroscopy Revealed Comparable Preservation of Bio-Components between FFPE Tissues and PFPE Tissues

FTIR microspectroscopy is an emerging technique in the field of ex-vivo diagnostics. FTIR spectra provide an overall estimation of the biochemical content inside tissues and can be analyzed to differentiate between disease states [12]. However, it has become apparent that methods for tissue preservation can affect or change the biochemical spectra and may lead to a false interpretation of the data $[12,14,15]$. We have assessed the bio-fingerprint region (900-1700 $\mathrm{cm}^{-1}$ ) to compare the effects of formalin and PAXgene tissue fixation on the spectral signatures of various bio-components in NOM and OSCC. Figure 5 represents the average spectra from each group of samples analyzed, and Table 5 depicts the band assignment $[12,15]$ of the analyzed spectral peaks ( $\mathrm{N}^{\text {spectra }}=100$, PFPE-NOM and FFPENOM; $\mathrm{N}^{\text {spectra }}=150$, PFPE-OSCC and FFPE-OSCC) for the bio-fingerprint region of each tissue sample group.
} 

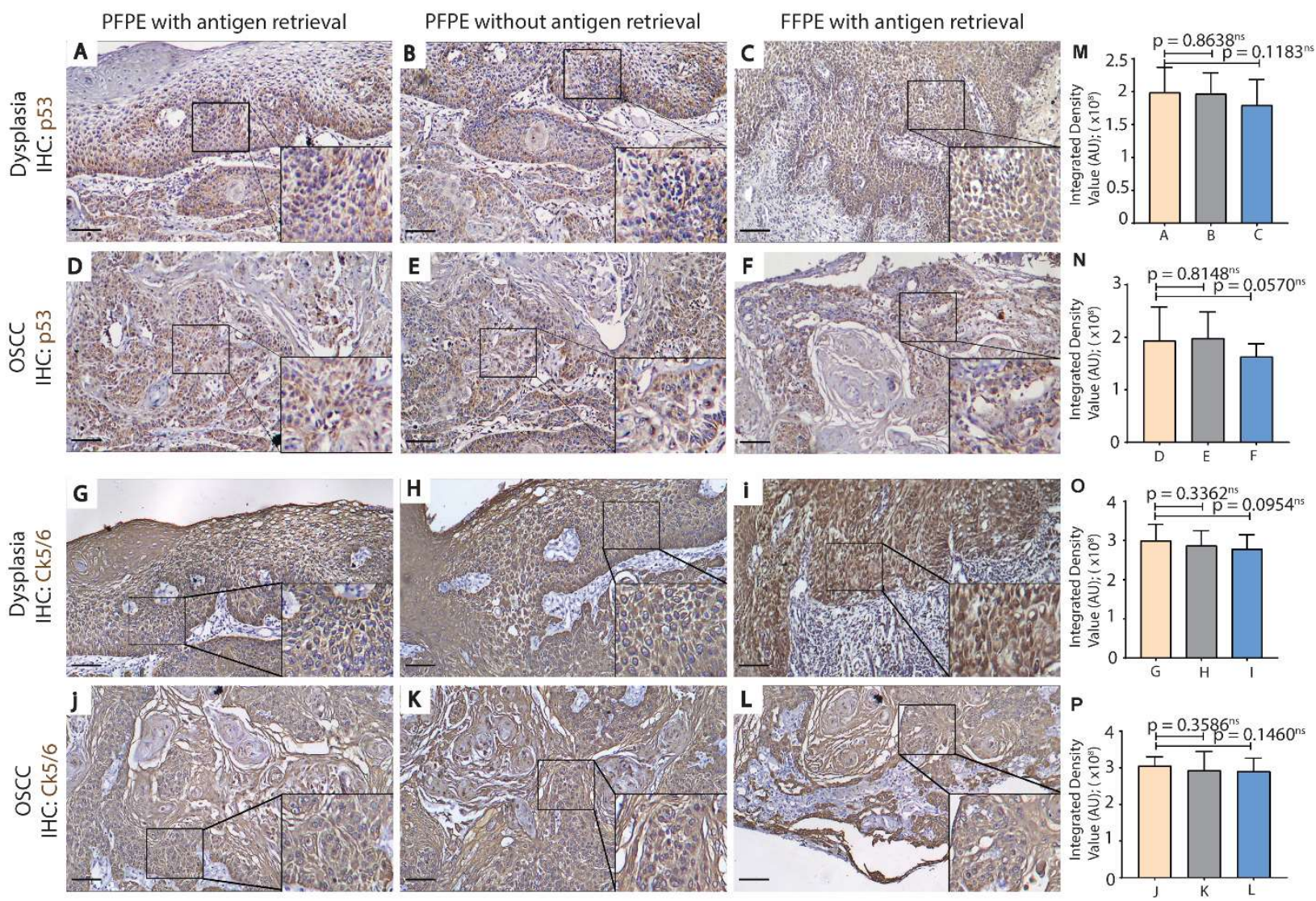

Figure 4. Heat-induced antigen retrieval is not essential for PFPE-Dysplasia and PFPE-OSCC tissues. Immunohistochemistry with antibodies against p53 (A-F) and CK5/6 (G-L) was performed on PFPE-Dysplasia (A,B,G,H), PFPE-OSCC (D,E,J,K), FFPE-Dysplasia (C,I), and FFPE-OSCC (F,L) tissues. Parallel tissue sections of PFPE-Dysplasia and PFPE-OSCC tissue were subjected to primary antibody (p53 or CK5/6) incubation with a prior antigen retrieval step (A,D,G,J) and without an antigen retrieval step $(\mathbf{B}, \mathbf{E}, \mathbf{H}, \mathbf{K})$. Antigen retrieval was performed on tissue sections of FFPE-Dysplasia (C,I) and FFPE-OSCC $(\mathbf{F}, \mathbf{L})$ before antibody (p53 or CK5/6) incubation (C,F). A similar intensity of the p53 immuno-staining was observed in basal and suprabasal layers of the epithelium in PFPE-Dysplasia tissues (corresponding integrated density value plot (M) for A-C) with (A) or without antigen retrieval (B), and for FFPE-Dysplasia (C). CK5/6 immuno-staining was observed homogenously (corresponding integrated density value plot (O) for G-I) through-out the epithelium in PFPE-Dysplasia tissues with (G) or without antigen retrieval (H), and for FFPE-Dysplasia (I). In PFPE-OSCC tissues, p53 immuno-expression $(\mathbf{D}, \mathbf{E})$ was found in epithelial islands and CK5/6 $(\mathbf{J}, \mathbf{K})$ immuno-expression was found in epithelial islands and keratin pearls, and the immunostaining and localization of both proteins were comparable to FFPE-OSCC tissues (C,F,I,K) (corresponding integrated density value plot (N,P) for $\mathbf{G}-\mathbf{I}$ and $\mathbf{J}-\mathbf{L}$, respectively). The incubation time for DAB chromogen was 2.5 min for the p53 antibody and $1 \mathrm{~min}$ for the CK5/6 antibody. Magnification $=10 \times$; Scale bar $=50 \mu \mathrm{m} . p<0.0001^{* * *} ; p<0.001^{* *}$; $p<0.05$ * (student $t$-test). Abbreviations: FFPE, formalin-fixed paraffin embedded; PFPE, PAXgene-fixed paraffin embedded; OSCC, oral squamous cell carcinoma; CK, cytokeratin; Intg., integrated.

The spectral region 1000-1200 $\mathrm{cm}^{-1}$ corresponds to absorption bands from several bio-molecules: carbohydrates, nucleic acids, and phospholipids. PAXgene tissue fixation exclusively preserved the $\mathrm{C}-\mathrm{O}$ stretch vibrations corresponding to glycogen at $1157 \mathrm{~cm}^{-1}$ in PFPE-NOM and $1155 \mathrm{~cm}^{-1}$ in PFPE-OSCC. A low-frequency band assigned to glycogen/carbohydrates was centered around $1010 \mathrm{~cm}^{-1}$ in the PAXgene- and NBF-fixed tissues. The $\sim 1115 \mathrm{~cm}^{-1}$ band assigned to RNA (C-O stretch of the ribose ring vibrations) was found in both PAXgene- and NBF-fixed tissue (Table 5, Figure 5). 

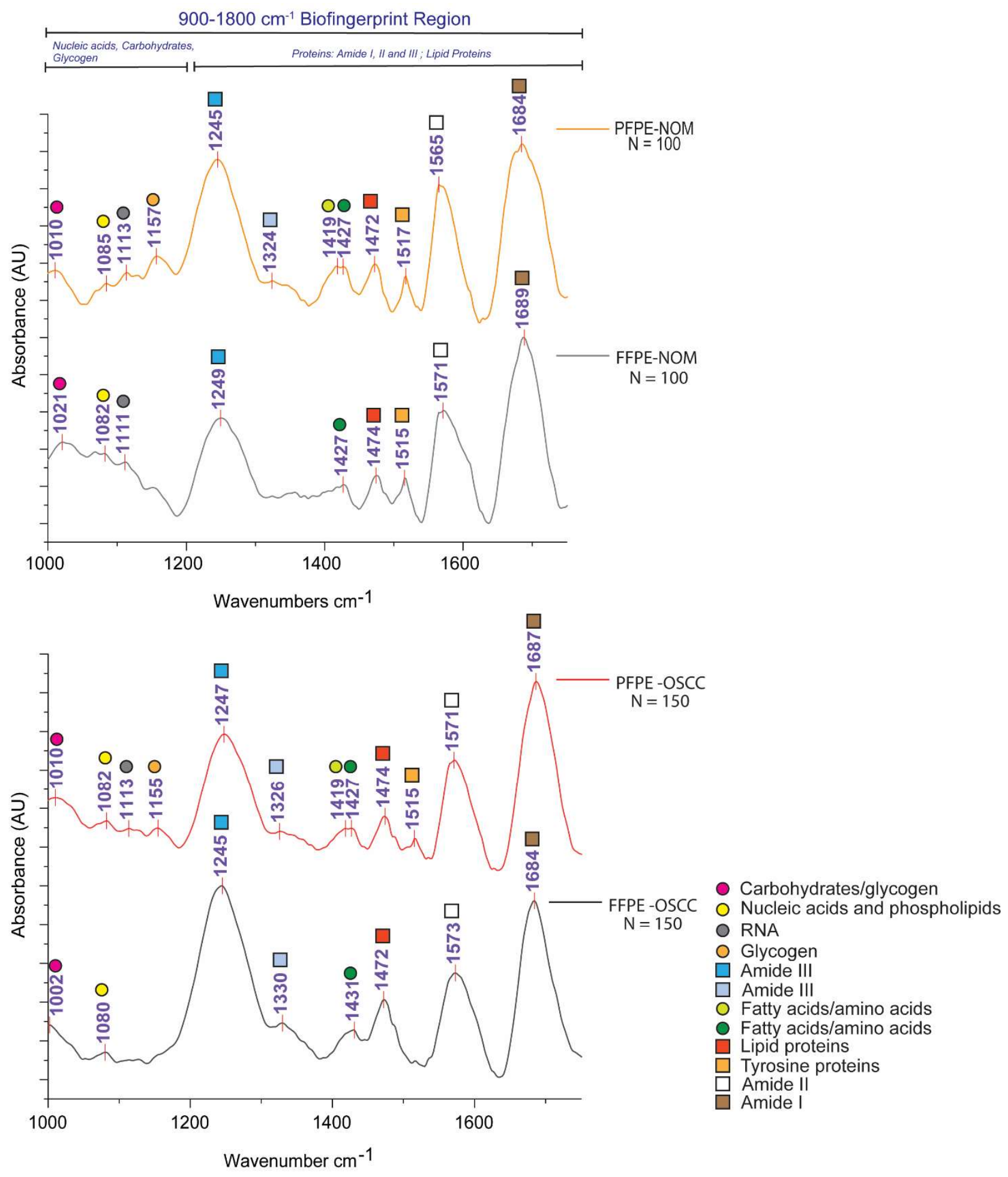

Figure 5. Average FTIR spectra from PFPE-NOM, FFPE-NOM, PFPE-OSCC, and FFPE OSCC tissues depicting the biofingerprint region $900 \mathrm{~cm}^{-1}-1700 \mathrm{~cm}^{-1}$. N $\mathrm{N}^{\text {spectra }}$ PFPE-NOM $=100 ; \mathrm{N}^{\text {spectra }}$ FFPE-NOM $=100 ; \mathrm{N}^{\text {spectra }}$ PFPE-OSCC $=$ 150; and N ${ }^{\text {spectra }}$ FFPE-OSCC $=150$. Abbreviations: FFPE, formalin-fixed paraffin embedded; PFPE, PAXgene-fixed paraffin embedded; OSCC, oral squamous cell carcinoma; NOM, normal oral mucosa. 
Table 5. Assignment of FTIR bands for PFPE and FFPE tissues.

\begin{tabular}{|c|c|c|c|c|c|c|}
\hline \multicolumn{7}{|c|}{ Band Positions $\left(\mathrm{cm}^{-1}\right)$} \\
\hline Vibration & $\begin{array}{l}\text { PFPE } \\
\text { NOM }\end{array}$ & $\begin{array}{l}\text { FFPE } \\
\text { NOM }\end{array}$ & $\begin{array}{l}\text { PFPE } \\
\text { OSCC }\end{array}$ & $\begin{array}{l}\text { FFPE } \\
\text { OSCC }\end{array}$ & $\begin{array}{c}\text { Assignment [12] (Malek } \\
\text { et al. 2014; Wang and } \\
\text { Wang 2021) }\end{array}$ & \\
\hline $\mathrm{COH}$ deformation & 1010 & 1021 & 1010 & 1002 & Glycogen/carbohydrates & 0 \\
\hline $\mathrm{PO}_{2}^{-}$asymmetric stretch & 1085 & 1082 & 1082 & 1080 & $\begin{array}{l}\text { Nucleic acids and } \\
\text { phospholipids }\end{array}$ & 0 \\
\hline $\mathrm{C}-\mathrm{O}$ stretch of the ribose ring & 1113 & 1111 & 1113 & 1115 & RNA & O \\
\hline C-O stretch & 1157 & $\times$ & 1155 & $\times$ & Glycogen & O \\
\hline \multirow[t]{2}{*}{ Amide III } & 1245 & 1249 & 1247 & 1245 & Protein & $\square$ \\
\hline & 1324 & $x$ & 1326 & 1330 & Protein & $\square$ \\
\hline \multirow[t]{2}{*}{$\mathrm{COO}^{-}$symmetric stretch } & 1419 & $x$ & 1419 & $\times$ & Fatty acids, amino acids & $\overline{0}$ \\
\hline & 1427 & 1427 & 1427 & 1431 & Fatty acids, amino acids & 0 \\
\hline $\mathrm{CH} 3$ and $\mathrm{CH} 2$ deformations & 1472 & 1474 & 1474 & 1472 & Lipid Proteins & $\square$ \\
\hline Ring CC stretch of tyrosine residues & 1517 & 1515 & 1515 & 1515 & Tyrosine Proteins & $\square$ \\
\hline $\mathrm{NH}$ bend $+\mathrm{C}-\mathrm{N}$ stretch Amide II & 1565 & 1571 & 1571 & 1573 & Proteins & $\square$ \\
\hline $\mathrm{C}=\mathrm{O}+\mathrm{NH}$ bend Amide I & 1684 & 1689 & 1687 & 1684 & Proteins & $\square$ \\
\hline
\end{tabular}

Colored shapes represent the assigned biomolecules, which can be correlated with spectra represented in Figure 5. Abbreviations: FFPE, formalin-fixed paraffin embedded; PFPE, PAXgene-fixed paraffin embedded; OSCC, oral squamous cell carcinoma; NOM, normal oral mucosa.

To understand the preservation of proteins by PAXgene fixation, we analyzed the spectral region between 1200 and $1700 \mathrm{~cm}^{-1}$. We observed the primary amide III band centered around $\sim 1245 \mathrm{~cm}^{-1}$ for the PAXgene- and NBF-fixed tissues. Additional amide III bands were observed at $1324 \mathrm{~cm}^{-1}$ in PFPE-NOM tissues and at $1326 \mathrm{~cm}^{-1}$ in PFPE OSCC tissues. The $1324 \mathrm{~cm}^{-1}$ band was absent in FFPE-NOM tissues; however, a $1330 \mathrm{~cm}^{-1}$ band was found in FFPE OSCC tissues (Table 5, Figure 5). These bands may correspond to the secondary structure of proteins corresponding to the amide III region [14]. The amide II band and amide I band were centered around $\sim 1571 \mathrm{~cm}^{-1}$ and $\sim 1684 \mathrm{~cm}^{-1}$, respectively, for all tissue groups.

A high-frequency band associated with $\mathrm{COO}^{-}$symmetric stretch vibrations centered around $1427 \mathrm{~cm}^{-1}$ assigned to fatty acids/amino acids was preserved in all tissue groups. Interestingly, the low-frequency band attributed to fatty acids centered at $1419 \mathrm{~cm}^{-1}$ was found exclusively in PAXgene-fixed NOM and OSCC tissues. Further, the band corresponding to $\mathrm{CH}_{3}$ and $\mathrm{CH}_{2}$ deformations assigned to lipids was found at $\sim 1472 \mathrm{~cm}^{-1}$ in all tissue groups.

\section{Discussion}

Oral buccal mucosal tissues have low tensile strength when compared to other intraoral sites such as the gingiva and hard palate [10]. Thus, it is not surprising that processing of oral buccal mucosal tissue for histological experiments is a tedious process and suffers from processing errors such as tissue fall-off from slides, wrinkling, and tissue tear. This leads to unnecessary experimental delay and loss of critical morphological or molecular information. We have successfully used the formalin-free PAXgene tissue fixation system for oral buccal mucosal tissue of normal and cancer morphology without compromising the quality of the histopathological analysis (Figure 2). In line with previous observations $[5,8,11]$, a slightly high eosinophilic reaction was observed in H\&E-stained PFPE tissues (Figure 2E,F), which did not interfere with the histopathological analysis. According to the participating oral pathologists in this study, architectural alterations in the surface epithelium and individual cell alterations [16] were detectable and comparable to formalin fixation in both H\&E-stained PFPE-NOM and PFPE-OSCC tissues.

Immunohistochemistry, by far, is the most routinely used method to analyze specific cancer biomarkers and, to an extent, has advanced our knowledge on oral cancer progression $[17,18]$. The heat-induced antigen retrieval step is a critical step in immuno- 
histochemistry; however, direct boiling of FFPE-NOM and FFPE-OSCC tissue in buffers results in the damage of tissues or fall-off of tissues from the slide. Several factors have been identified to contribute to the problem of tissue fall-off from slides, such as inadequate fixation, uneven sectioning and drying, and poor quality of adherent and uncleaned slides [19]. Even after taking care of the aforementioned factors, we observed recurrent tissue fall-off from slides of FFPE-NOM and FFPE-OSCC samples after boiling (Tables 3 and 4). PAXgene-fixed tissues show a slight reduction in tissue-fall from slides after boiling (Table 4). As PAXgene tissue fixation systems do not form crosslinks with the tissues, we removed the antigen-retrieval step for the PFPE-NOM and PFPE-OSCC samples and successfully optimized the immunohistochemistry protocol for oral cancer biomarkers p53 and CK5/6. Skipping the antigen retrieval step significantly reduced the problem of tissue fall-off from slides (Table S3). Although antigen retrieval by boiling is an excellent way to gain the immunoreactivity of antibodies, it also damages the morphology of the tissue to some extent, which may hinder diagnosis. Further, the consensus based on previous observations on FFPE tissue is that every antigen requires a "tailor-made" retrieval condition, which is highly prone to technical errors, leading to irreproducibility of the data [20]. Our experiments showed improved quality of immuno-staining of both p53 and CK5/6 in basal and suprabasal epithelial layers for PFPE-NOM tissues (with or without antigen retrieval) over FFPE-NOM tissues (with antigen retrieval) (Figure 4). This is an important observation as any redundancies in the control group may lead to incorrect interpretation of the expression of cancer-associated proteins (in this case- p53 and CK5/6), false diagnosis, and incorrect statistics in comparative datasets. For dysplasia and OSCC samples, the immuno-staining in PFPE tissues was comparable to FFPE tissues as per the oral-pathologists' interpretation (Figure 4). However, a semi-quantitative analysis on the density value of the immuno-stains shows less expression of p53 and CK5/6 in FFPE-tissues (Figures 3 and 4). Recently, concerns have been raised regarding the irreproducibility of the immunohistochemical data for studying prognostic features in OSCC [21,22]. The 8th edition of the American Joint Committee on Cancer (AJCC) staging has reinforced focus on histo-morphological prognostic features, such as tumor stroma ratio, depth of invasion, and extranodal extension, to study the prognosis of OSCC [22]. From our experiments, it can be inferred that PAXgene tissue fixation of oral mucosa tissues can be successfully implemented in histo-morphological and molecular pathology studies, with enhanced staining characteristics and minimal risk of irreproducibility.

Next, we investigated the preservation of biochemical content of oral samples using FTIR microspectroscopy. We measured and analyzed spectra from pathologically similar region of interests from grouped tissues of NOM and OSCC fixed with either NBF or the PAXgene tissue fixation system (Figure 1). PAXgene fixation, and not NBF fixation, showed preservation of the $\mathrm{C}-\mathrm{O}$ vibrations attributable to glycogen (Figure 5 and Table 5). Previous histological studies have shown a higher glycogen expression in oral dysplasia when compared to normal, and it is an indicator of cancer progression [23,24]. Structural alterations in nucleic acids, and increased transcriptional activity pertaining to increase in RNA, was previously reported in various studies on OSCC $[17,24]$. The RNA band corresponding to the $\mathrm{C}-\mathrm{O}$ stretch of the ribose ring was preserved in both PAXgene and NBF-fixed tissues (Figure 5 and Table 5). Further, prior studies have shown PAXgene fixation is superior in preserving RNA integrity, particularly in low-yield samples for molecular experiments $[3,5,25]$. It also was reported that the PAXgene-fixed RNA has better RT-PCR efficiency than NBF fixation and was comparable to snap-frozen samples, irrespective of the length of the mRNA, in a wide variety of cancerous tissues, including squamous cell carcinoma $[5,25,26]$. Further in-depth comparative studies are warranted in oral tissue to understand the effect of PAXgene fixation on RNA integrity and downstream analysis such as RT-PCR and RNA sequencing.

In terms of the preservation of proteins, all three amide bands (amide I, amide II, and amide III) were preserved in both PAXgene- and NBF-fixed tissues. We also observed an additional band for amide III centered around $\sim 1324 \mathrm{~cm}^{-1}$ in both PFPE-NOM and PFPE 
OSCC tissues (Table 5). These bands correspond to the alpha-helical secondary structure of proteins [14]. The amide I region is generally used for studying the secondary structure modifications in proteins, whereas the amide III region is comparatively neglected due to the low signal. However, it was previously described that the secondary structures of proteins have more resolved differences in their amide III spectra [14,27]. Recent studies have indicated that the secondary structure modifications are a direct measure of the gainof-function mutations of the amino acids of proteins leading to cancer progression [28,29]. Furthermore, alterations in secondary structure of proteins, to an extent, modulates the phosphorylation of proteins [30]. Recently, a MS-based approach showed 62 unique phosphorylated sites in the tumor epithelium of OSCC [31]. In this regard, prior studies have shown enhanced preservation of phosphorylated proteins in PAXgene-fixed tissues than formalin-fixed tissues [26,32]. Further studies on secondary structure alterations in PAXgene-fixed NOM and OSCC tissues may provide new insights into the protein biomarkers of oral cancer progression.

\section{Conclusions}

To the best of our knowledge, this is the first time that PAXgene and NBF fixation of oral tissues were simultaneously compared in terms of morphology (histology, immunohistochemistry) and the sample biochemical variations arising from different methods of fixation (FTIR). Our study demonstrates that for fragile tissues such as oral buccal mucosa, which are prone to processing and handling errors, PAXgene tissue fixation systems can be implemented for routine histological and immunohistochemistry experiments without compromising on the quality of the morphological diagnosis. PAXgene fixation also ensured the preservation of several important biocomponents (nucleic acids, lipids, and proteins) as revealed by FTIR microspectroscopy. This information will save time in the clinics while collecting and processing the oral tissue for molecular diagnostic purposes as a second fixative for the preservation of nucleic acids may not be required. As medical decision-making moves towards personalized diagnostics by obtaining a broader spectrum of information from the same tissue, the PAXgene tissue fixation system may help improve the efficiency of diagnosis.

Supplementary Materials: The following are available online at https://www.mdpi.com/article/10 .3390/biom11060889/s1, Table S1: Percentage loss of tissue area from epithelium and sub-epithelium regions due to tissue tear or wrinkling, Table S2: Experimental Conditions Used for Optimization of Antigen Retrieval for Immunohistochemistry Application, Table S3. Documentation of cases of tissue section fall-off from slides during sample processing steps for immuno-histochemical staining experiments for PFPE tissue without antigen retrieval, Methods S1: Immunohistochemistry.

Author Contributions: Conceptualization, P.L; methodology, P.L., S.M., B.G., D.D., M.P., R.R.P.; software, P.L, B.G., S.M.; validation, P.L., S.M. and B.G.; formal analysis, P.L., S.M., B.G., M.P., R.R.P., B.L.; investigation, P.L., S.M., B.G., J.C.; resources, P.L.,B.L., S.K.V., J.C.; data curation, P.L., S.M.; writing-original draft preparation, P.L.; writing-review and editing, P.L., S.M., B.G., D.D., B.L., S.K.V., M.P., R.R.P., J.C.; visualization, P.L.; supervision, P.L., J.C.; project administration. P.L.; funding acquisition, P.L., B.L., M.P., S.K.V., J.C. All authors have read and agreed to the published version of the manuscript.

Funding: The study was funded by institute postdoctoral fellowship contingency fund (18MMPD101) of IIT Kharagpur to P.L., West Bengal DST grant (Ref. Memo no. 151(SANC.)/ST/P/S\&T/9G32/2016) to J.C., and Science and Engineering Board-Core Research Grant (CRG/2020/002687) to B.L., S.K.V. and M.P.

Institutional Review Board Statement: The study was conducted according to the guidelines of the Declaration of Helsinki. This study was performed with the informed consent of all individuals and approved by the institutional ethics committee (GNIDSR/IEC/07/16).

Informed Consent Statement: Informed consent was obtained from all subjects involved in the study. 
Data Availability Statement: All data pertaining to the manuscript is given in the main-text or supplementary data. Additional information can be requested from the corresponding author if and when required.

Acknowledgments: The authors would like to acknowledge the MDS students from GNIDSR, Kolkata, and R. Ahmed Medical College, Kolkata, for their active participation in the collection of samples.

Conflicts of Interest: The authors declare no conflict of interest. The funders had no role in the design of the study; in the collection, analyses, or interpretation of data; in the writing of the manuscript, or in the decision to publish the results.

\section{References}

1. Hicks, D.G.; Boyce, B.F. The challenge and importance of standardizing pre-analytical variables in surgical pathology specimens for clinical care and translational research. Biotech. Histochem. 2012, 87, 14-17. [CrossRef] [PubMed]

2. Howat, W.J.; Wilson, B.A. Tissue fixation and the effect of molecular fixatives on downstream staining procedures. Methods 2014, 70, 12-19. [CrossRef]

3. Kap, M.; Smedts, F.; Oosterhuis, W.; Winther, R.; Christensen, N.; Reischauer, B.; Viertler, C.; Groelz, D.; Becker, K.-F.; Zatloukal, K.; et al. Histological assessment of PAXgene tissue fixation and stabilization reagents. PLoS ONE 2011, 6, e27704. [CrossRef] [PubMed]

4. Gillard, M.; Tom, W.R.; Antic, T.; Paner, G.P.; Lingen, M.W.; VanderWeele, D.J. Next-gen tissue: Preservation of molecular and morphological fidelity in prostate tissue. Am. J. Transl. Res. 2015, 7, 1227-1235.

5. Groelz, D.; Sobin, L.; Branton, P.; Compton, C.; Wyrich, R.; Rainen, L. Non-formalin fixative versus formalin-fixed tissue: A comparison of histology and RNA quality. Exp. Mol. Pathol. 2013, 94, 188-194. [CrossRef] [PubMed]

6. Masuda, N.; Ohnishi, T.; Kawamoto, S.; Monden, M.; Okubo, K. Analysis of chemical modification of RNA from formalin-fixed samples and optimization of molecular biology applications for such samples. Nucleic Acids Res. 1999, 27, 4436-4443. [CrossRef]

7. Mc Sherry, E.A.; Mc Goldrick, A.; Kay, E.W.; Hopkins, A.M.; Gallagher, W.M.; Dervan, P.A. Formalin-fixed paraffin-embedded clinical tissues show spurious copy number changes in array-CGH profiles. Clin. Genet. 2007, 72, 441-447. [CrossRef]

8. Mathieson, W.; Marcon, N.; Antunes, L.; Ashford, D.A.; Betsou, F.; Frasquilho, S.G.; Kofanova, O.A.; McKay, S.C.; Pericleous, S.; Smith, C.; et al. A Critical Evaluation of the PAXgene Tissue Fixation System: Morphology, Immunohistochemistry, Molecular Biology, and Proteomics. Am. J. Clin. Pathol. 2016, 146, 25-40. [CrossRef]

9. Pegg, D.E. The relevance of ice crystal formation for the cryopreservation of tissues and organs. Cryobiology 2010, 60, S36-S44. [CrossRef] [PubMed]

10. Choi, J.J.E.; Zwirner, J.; Ramani, R.S.; Ma, S.; Hussaini, H.M.; Waddell, J.N.; Hammer, N. Mechanical properties of human oral mucosa tissues are site dependent: A combined biomechanical, histological and ultrastructural approach. Clin. Exp. Dent. Res. 2020, 6, 602-611. [CrossRef]

11. Belloni, B.; Lambertini, C.; Nuciforo, P.; Phillips, J.; Bruening, E.; Wong, S.; Dummer, R. Will PAXgene substitute formalin? A morphological and molecular comparative study using a new fixative system. J. Clin. Pathol. 2013, 66, 124-135. [CrossRef]

12. Malek, K.; Wood, B.R.; Bambery, K.R. FTIR Imaging of Tissues: Techniques and Methods of Analysis. In Optical Spectroscopy and Computational Methods in Biology and Medicine; Baranska, M., Ed.; Springer: Dordrecht, The Netherlands, $2014 ;$ pp. 419-473.

13. PAXgene Tissue FIX Container Product Circular-PreAnalytiX www.preanalytix.com. Available online: https://www. preanalytix.com/storage/download/_ProductResources_/Handbooks/HB-1477-001_1074355_HB_Tissue_all_FIX_Container_ 0213_WW.pdf (accessed on 26 February 2021).

14. Cai, S.; Singh, B.R. A Distinct Utility of the Amide III Infrared Band for Secondary Structure Estimation of Aqueous Protein Solutions Using Partial Least Squares Methods. Biochemistry 2004, 43, 2541-2549. [CrossRef] [PubMed]

15. Wang, R.; Wang, Y. Fourier Transform Infrared Spectroscopy in Oral Cancer Diagnosis. Int. J. Mol. Sci. 2021, 22, 1206. [CrossRef] [PubMed]

16. Geetha, K.M.; Leeky, M.; Narayan, T.V.; Sadhana, S.; Saleha, J. Grading of oral epithelial dysplasia: Points to ponder. J. Oral Maxillofac. Pathol. JOMFP 2015, 19, 198-204. [CrossRef]

17. Choi, P.; Jordan, C.D.; Mendez, E.; Houck, J.; Yueh, B.; Farwell, D.G.; Futran, N.; Chen, C. Examination of oral cancer biomarkers by tissue microarray analysis. Arch. Otolaryngol. Head Neck Surg. 2008, 134, 539-546. [CrossRef]

18. Almangush, A.; Heikkinen, I.; Mäkitie, A.A.; Coletta, R.D.; Läärä, E.; Leivo, I.; Salo, T. Prognostic biomarkers for oral tongue squamous cell carcinoma: A systematic review and meta-analysis. Br. J. Cancer 2017, 117, 856-866. [CrossRef]

19. Shi, S.R.; Shi, Y.; Taylor, C.R. Antigen retrieval immunohistochemistry: Review and future prospects in research and diagnosis over two decades. J. Histochem. Cytochem. 2011, 59, 13-32. [CrossRef] [PubMed]

20. Ezaki, T. Antigen retrieval on formaldehyde-fixed paraffin sections: Its potential drawbacks and optimization for double immunostaining. Micron 2000, 31, 639-649. [CrossRef]

21. Mascitti, M.; Rubini, C.; De Michele, F.; Balercia, P.; Girotto, R.; Troiano, G.; Lo Muzio, L.; Santarelli, A. American Joint Committee on Cancer staging system 7th edition versus 8th edition: Any improvement for patients with squamous cell carcinoma of the tongue? Oral Surg. Oral Med. Oral Pathol. Oral Radiol. 2018, 126, 415-423. [CrossRef] 
22. Mascitti, M.; Zhurakivska, K.; Togni, L.; Caponio, V.C.A.; Almangush, A.; Balercia, P.; Balercia, A.; Rubini, C.; Lo Muzio, L.; Santarelli, A.; et al. Addition of the tumour-stroma ratio to the 8th edition American Joint Committee on Cancer staging system improves survival prediction for patients with oral tongue squamous cell carcinoma. Histopathology 2020, 77, 810-822. [CrossRef]

23. Isacsson, G.; Shear, M. Content and distribution of glycogen in oral epithelial dysplasia. Scand. J. Dent. Res. 1981, 89, 79-88. [CrossRef] [PubMed]

24. Sabbatini, S.; Conti, C.; Rubini, C.; Librando, V.; Tosi, G.; Giorgini, E. Infrared microspectroscopy of Oral Squamous Cell Carcinoma: Spectral signatures of cancer grading. Vib. Spectrosc. 2013, 68, 196-203. [CrossRef]

25. Southwood, M.; Krenz, T.; Cant, N.; Maurya, M.; Gazdova, J.; Maxwell, P.; McGready, C.; Moseley, E.; Hughes, S.; Stewart, P.; et al. Systematic evaluation of PAXgene ${ }^{\circledR}$ tissue fixation for the histopathological and molecular study of lung cancer. J. Pathol. Clin. Res. 2020, 6, 40-54. [CrossRef]

26. Viertler, C.; Groelz, D.; Gündisch, S.; Kashofer, K.; Reischauer, B.; Riegman, P.H.; Winther, R.; Wyrich, R.; Becker, K.F.; Oelmüller, U.; et al. A new technology for stabilization of biomolecules in tissues for combined histological and molecular analyses. J. Mol. Diagn. 2012, 14, 458-466. [CrossRef]

27. Singh, B.; DeOliveira, D.; Fu, F.-N.; Fuller, M. Fourier transform infrared analysis of amide III bands of proteins for the secondary structure estimation; SPIE: Bellingham, WA, USA, 1993; Volume 1890.

28. Khan, S.; Vihinen, M. Spectrum of disease-causing mutations in protein secondary structures. BMC Struct. Biol. 2007, 7, 56. [CrossRef]

29. Tikhonov, D.; Kulikova, L.; Kopylov, A.; Malsagova, K.; Stepanov, A.; Rudnev, V.; Kaysheva, A. Super Secondary Structures of Proteins with Post-Translational Modifications in Colon Cancer. Molecules 2020, 25, 3144. [CrossRef]

30. Johnson, L.N.; Barford, D. The effects of phosphorylation on the structure and function of proteins. Annu. Rev. Biophys. Biomol. Struct. 1993, 22, 199-232. [CrossRef]

31. Winck, F.V.; Belloni, M.; Pauletti, B.A.; de Lima Zanella, J.; Domingues, R.R.; Sherman, N.E.; Paes Leme, A.F. Phosphoproteome analysis reveals differences in phosphosite profiles between tumorigenic and non-tumorigenic epithelial cells. J. Proteom. 2014, 96, 67-81. [CrossRef] [PubMed]

32. Gündisch, S.; Schott, C.; Wolff, C.; Tran, K.; Beese, C.; Viertler, C.; Zatloukal, K.; Becker, K.-F. The PAXgene $\left({ }^{\circledR}\right)$ tissue system preserves phosphoproteins in human tissue specimens and enables comprehensive protein biomarker research. PLoS ONE 2013, 8, e60638. [CrossRef] [PubMed] 